\title{
PRInK: Environmental virtual interactive based education and learning model for STEM motivation
}

\author{
Jamaiah Yahaya ${ }^{1}$ (D) Sazrol Fadzli ${ }^{1}$ - Aziz Deraman² - Noor Zaitun Yahaya ${ }^{2}$. \\ Lilia Halim ${ }^{3}$ - Izhar Abadi Ibrahim Rais ${ }^{4}$ Siti Rohana Ahmad Ibrahim ${ }^{1}$
}

Received: 29 June 2021 / Accepted: 31 October 2021 /Published online: 15 November 2021

(c) The Author(s) 2021

\begin{abstract}
Pollution from quarry activities has a substantial environmental impact on many countries. This issue should be addressed accordingly as its impact may introduce various health-related problems to the surrounding community. One alternative is to increase awareness for the younger generation and society at large. However, environmental data modelling, specifically on quarry activities, has thus far targeted engineers and professionals, not school children, such as for knowledge exploration or learning material. At the same time, the number of students enrolling in STEM courses is continuously declining. Hence, this research aims to develop the environmental virtual interactive based education and learning model called PRInK to foster STEM education. Five components of the proposed model were identified: a) Computer-Assisted Learning; b) Motivation Level; c) Green Environmental Data; d) Learning Outcome; and e) Problem Context. The actual environmental scientific data were used in the simulation and visualisation. Experts in these fields verified the components. The result of the analysis reveals 17 groups of elements, which were further categorised into 58 sub-elements. The model then was validated through prototype development and users validation. The testing and validation of the prototype were carried out on secondary school children, with the results proving the usability and practicality of the model and showed the increased STEM motivation and interest. The PRInK model and the prototype increase society's awareness about environmental issues starting from school, increase STEM interest and improve the overall quality of life through a shared understanding for future generations.
\end{abstract}

Keywords Educational and learning model - Green environmental data · Environmental virtual interactive $\cdot$ Simulation and visualisation $\cdot$ Knowledge exploration $\cdot$ STEM motivation

Jamaiah Yahaya

jhy@ukm.edu.my

Extended author information available on the last page of the article 


\section{Introduction}

Fewer students enrol in STEM education, and this trend appears in Malaysia (Shahali et al., 2017). Therefore, whether the Malaysian education system can produce enough STEM graduates to power the nation is now a big question mark. Malaysia is short of 236,000 professionals required in STEM-related fields and the projected requirement for scientists and engineers by 2020. To increase student and teacher interest in STEM education, the Ministry of Education of Malaysia (MOE) has developed a Malaysia Education Blueprint (2013-2025) or MEB with ten thrusts to continue educational excellence (Bahrum et al., 2017).

Nowadays, technological advancements have paved the way towards enhanced knowledge discovery in education-enabling simulation and visualisation (S\&V) to become a standard approach for problem-solving, games, training, tutorials, and tests (Zelaya-Floyd, 2017). The instructional design also benefits from blended learning (Stapa \& Mohammad, 2019), introduced in education. Unlike traditional methods, S\&V, a form of computer-assisted instruction (CAI), encourages initiative-taking in students when it comes to learning. This method enables students to interact, manipulate, and observe using actual data to solve real-world problems. Through S\&V, students experience first-hand real-life simulations, which would be impossible to achieve otherwise. Ultimately, using S\&V, students will capitalise on discovering knowledge via real-world scenarios representing complex data. Higher learning outcomes are generated in this way, and students will enjoy active, valuable learning experiences (Rutten et al., 2012).

Today's users are very dynamic and diverse, that although simulations have proven benefits, the needs of such users are not sufficiently met. Applying simulation in school settings requires greater engagement and technological ability from both student and educator than other passive modes of instruction. However, according to Smetana and Bell (2012), research in this area is still limited. Current technological advancements target expert users and not laypeople or school children. Simulation and visualisation usually require greater engagement from both parties - the designer and the user. It is, therefore, different from other passive forms of instruction in education.

Based on the identified gap, the following research objectives were set:

i. To determine the components required for learning about the quarry industry's impact on the environment.

ii. To develop an environment virtual interactive based education and learning model.

iii. To validate the model through prototype and user's validation.

The remaining parts of this paper are organised as follows: Section 2 outlines the background works, material, and methods. Section 3 presents the results of this study which focuses on the PRInK model, a model for environmental virtual interactive based education and learning for STEM motivation or, in short, 
a PRInK model. In Section 4, the model's validation is discussed, followed by a discussion in Section 5. Finally, section 6 concludes this paper with a conclusion.

\section{Background work}

\subsection{Materials}

The literature review covers the five motivational components: computer-assisted learning (CAL), green environment data, motivation level, learning outcome, and problem context (adaption to the scenarios).

\subsubsection{Computer-assisted learning (CAL)}

Simulation and visualisation are identified as components that could motivate school children to learn STEM subjects and courses. As per the Ministry of Education Malaysia (2015), this component could help uplift learning outcomes while a new partnership model could help the industry lead curriculum design and delivery.

The environmental issues were applied as the STEM concept, and the students were tasked with problem-solving and exploring these issues using real-world data (Ministry of Education Malaysia, 2016). For example, humans openly excavate high land or hills to obtain slate, limestone, or stones for building and construction purposes, and these sites are called quarries. The activities carried out in quarries have local, regional, and global implications. Nevertheless, drilling, crushing, blasting, material handling, and material transportation emit particles, noise, and vibration, damaging the environment (Yahaya et al., 2016).

According to Greca et al. (2014), the simulation uses a computational mathematical model to represent a system's dynamic behaviour. Through simulation, students will benefit from knowledge-centred, learner-based, and inquiry-based instruction. In addition, this tool can be used to learn conceptual changes in science (Srisawasdi \& Panjaburee, 2015).

On the other hand, visualisation is defined as using images to represent a nonoptical phenomenon (Hidalgo-Céspedes et al., 2016). Humans can better perceive quantitative data through visualisation. Graphics can more easily display and help process information, debug computational code, enable the adoption of novel analysis, validate models, and communicate the discovery of new knowledge. Visualisation is also a form of active learning that can help STEM students master fundamental computational concepts and skills (Chi \& Jain, 2011). In CAL, computers play a central role in information delivery, instruction, and direct learner engagement and interaction. Essentially, S\&V automatically and interactively presents instructional programmes to learners through computers. Researchers can now integrate S\&V and CAL to enhance the learning effectiveness of complex real-world concepts that would otherwise be too difficult, dangerous, or time-consuming to conduct in a conventional learning setting (Smetana \& Bell, 2012). Hence, students can study complex systems without any hassle (Greca et al., 2014) and obstacles that disrupt the 
smoothness of the face-to-face learning process to see for themselves various natural phenomena for learning.

The previous study has revealed that STEM learning could be enhanced through learning about the quarry environment (Śliwińska-Wyrzychowska et al., 2015). Since the actual practice of quarrying imposes physical and financial constraints in the engineering classroom, a simulation of the activity is especially useful. The same simulations could also be used among school children to motivate them to learn about science and technology (Watson et al., 1997). A new positive-response quarry-based simulation was introduced by Akkoyun (2017) and Standridge (1985). However, these studies only simulated certain quarrying activities, and the benefits of this simulation still require scientific proof.

\subsubsection{Green environmental data}

Learning in the twenty-first-century demands students to apply primary knowledge to self-learn, question, and search the main concepts of a course using connections to real-life scenarios, experiments, and testing (Açişli et al., 2011). In this case, $\mathrm{S} \& \mathrm{~V}$ is seen as the perfect vehicle for students to visualise and adapt the information to suit the twenty-first-century learning system and the 4th Industrial Revolution in Education. Moreover, $\mathrm{S} \& \mathrm{~V}$ is a powerful, elegant solution for understanding environmental processes (Huang et al., 2004). To date, many models driven by geographic data, heterogeneous data, high-dimensional data, historical data, tables of probabilities, etc., have been proposed. Visualisation simplifies the presentation of data (Chi \& Jain, 2011) to the users. The education system is now aligning with the 4th Industrial Revolution. The goal is to train students to become proficient at correlating and applying various knowledge branches in different contexts, developing "something" out of it, and seeing how it connects to the real world.

The environment is defined as anything surrounding an organisation, such as humans, land, water, air, natural resources and flora and fauna. However, the surroundings are not limited to an organisation but could also extend to global systems (ISO14004, 2016). Meanwhile, environmental data refers to "any parameters or pieces of information collected or produced from measurements, analyses, or models of environmental processes, conditions, and effects of pollutants on human health and the environment, including results from laboratory analyses or experimental systems representing such processes and conditions" (Persistent Organic Pollutants, 2019). The simulation process involves the post-processing of data in which data is analysed and visualised; hence, environmental information is crucial to the ecological modelling process. Furthermore, environmental data can now be better represented to preserve the environment through approaches such as data mining, application development, and knowledge retrieval and discovery (Yahaya et al., 2017).

In past studies, environmental data has been applied over various scenarios, including environmental planning and management, traffic impact analyses, earthquake disaster simulations, and manufacturing process optimisation. For example, sand, earth minerals, rocks, or gravel are cut, dug, or blasted to produce construction or building material in quarrying. The noise, vibrations, and particles (referred 
to later in this study as PVN) can be modelled as environmental data and linked to other forms of ecological data objects. Yahaya et al. (2016) incorporated green environmental data into a primary repository to increase shareability, handling, accessibility among various user groups and scientific data. However, the PVN data, according to experts, is limited to local formats and requirements.

Additionally, the computational models of environment quality measurement, with particles, vibration and noise as the parameters or variables, have been proposed (Yahaya et al., 2017). Past green environmental data-based simulations focused on setting specific input parameters in a selected quarry. Still, they did not consider learning outcomes for students, which is a gap this study aims to address.

\subsubsection{Motivation level}

Based on the literature review, one of the components that can encourage school children to learn STEM is motivation. Similar works recommend increasing student motivation to study STEM subjects by increasing their involvement in STEM fields (Rosenzweig \& Wigfield, 2016). A person who is motivated has the desire to achieve a set objective. The success or failure of an undertaking relies on their motivation. According to experts, students with no motivation will not learn effectively. Students must also be interested in a subject before they are motivated to learn about it (Hung et al., 2013). Comprehensive studies on this subject have revealed that highly motivated students thrive in challenging situations, do not easily give up, and are more willing to learn (Rosenzweig \& Wigfield, 2016). Previous studies proved that $\mathrm{S} \& \mathrm{~V}$ is an excellent tool to motivate students to learn (Bilbokaite, 2016; Lee \& Pachmayer, 2016). As a result, students behave better and look forward to learning and attending school. Students are more motivated when they can visualise what it is they are learning about. Besides, the extent of interaction during simulation sessions has been linked to the motivation level.

Models and a series of interventions have been developed to increase student motivation (Dawley \& Dede, 2014; Cai et al., 2014). Some examples are the ARCS model and the Dick and Carey Model. Both have proven valuable in systematically improving student motivation and their wide adaptation in designing, developing, and evaluating motivational strategies (Göksu et al., 2017). Meanwhile, the 5E instructional model has been shown to motivate students and produce successful scientific simulations (Göksu et al., 2017; Cantrell et al., 2006).

\subsubsection{Learning outcome}

The knowledge and skills required of STEM students are outlined in the Learning Outcome. The knowledge and skills that the students demonstrate are a result of their exposure to the educational environment. Simulations have been positively or neutrally linked to the learning outcome. This promising finding has prompted education institutions worldwide to apply simulations in class for better learning outcomes (Liaw et al., 2012). The first step to establishing a simulation-based learning experience is developing written participant objectives (Lioce et al., 2013). These objectives guide educators to determine whether the simulation helps achieve a 
learning outcome. Identifying the facilitation method, the appropriate scenario, and the simulation fidelity is critical to ensure participant objectives are met. The course integration, the desired learning context, and the facilitator's role will shape the use of simulation in this sector (de Smale et al., 2016). On top of that, there is a need to show that the learning outcomes are achieved. At present, students fail to visualise a successful learning outcome and fail to solve their learning problems (Lasiun, 2016) precisely.

\subsubsection{Problem context (adaption to scenario)}

The skills demanded by the twenty-first-century include problem-solving involvement, communication, data analysis and interpretation, task management, task prioritisation, model understanding and assessment, and ensuring wellbeing and safety (Sattar et al., 2016). Although previous studies have put forth many quarrying scenarios whilst applying $\mathrm{S} \& \mathrm{~V}$, these simulations are not intended for a school-going audience. However, quarrying activities are real-world STEM activities introduced in education and learning to benefit students. Now, students are only being told of the pollution and damage certain activities could wreak on the environment, but the type of pollution is unspecified (Abdullah et al., 2011). The skills to visualise the harmful outcome of quarrying activities based on pollution, vibration, and noise are omitted and not explored in school education.

\subsubsection{E instructional model}

The 5E instructional model or the $5 \mathrm{E}$ model refers to the five learning principles, i.e., engage, explore, explain, elaborate, and evaluate. According to Manser and Kilgo (2015), this model assists in instructional design to enhance learning outcomes through student enquiry skills while increasing student focus and motivation. Several instructional and learning models are available, such as the 7E learning model, ADDIE, ARCS, and Dick and Carey. Still, the 5E model is considered the most well-known instructional design adoption by previous researchers. In contrast, the 7E model focuses on learning design; the 5E model emphasises the instructional design, which is the target of our research. At the same time, the 5E Instructional Model is used in the Malaysian education system (Pusat STEM Negara, 2020; Ministry of Education Malaysia (2016). In addition, previous studies have revealed the capability of the $5 \mathrm{E}$ model in enhancing academic success while at the same time increasing the social skills of schoolchildren via enhanced critical thinking (Açişli et al., 2011; Göksu et al., 2017).

The 5E instructional model focuses on students and encompasses five main phases:

1. Engage-in this first phase of the learning cycle, student understanding, prior knowledge, and knowledge gaps are focused on. It also aims to foster student interest in upcoming concepts. 
2. Explore-during this phase, students explore new concepts through a concrete learning experience. They will be asked to go through a scientific method and communicate it to make an observation.

3. Explain-During this phase, the teacher helps the students synthesise new knowledge and ask questions if they need further clarification. Additional tools such as video, computer software, or other aids are beneficial to boost understanding.

4. Elaborate-the elaboration phase of the 5E model focuses on giving space to students to apply what they have learned. This activity helps them develop a deeper understanding.

5. Evaluate-in this phase, student assessment is conducted via formal and informal assessment. The types of evaluation include self-assessment, peer-assessment, writing assessment, or examinations.

The $5 \mathrm{E}$ instructional model and the quarry environment discussed in previous sections are integrated into this study. Computational models of green environmental data represent natural process formulations that can be shared, discovered, manipulated, accessed by, and expanded to other domains. Such a computational model was developed to focus on the environmental quality measurements of the quarry industry (Yahaya et al., 2017). These computational models define scenarios of quarrying activities, which are material handling, drilling, blasting, crushing and transportation, and they are closely linked to STEM knowledge in education. In other words, these simulations can help students obtain a better understanding and predict and explore the impact of natural processes based on specific input parameters. Moreover, these scenarios could be categorised according to the $5 \mathrm{E}$ instructional model: engagement, exploration, explanation, elaboration, and evaluation. Therefore, the entire simulation could be adapted to motivate students to learn STEM subjects.

\subsection{Method}

This research was conducted in five main phases: conceptual design and requirement specification; green data model \& architecture design; visualisation and simulation design and modelling; prototype design and development; and prototype evaluation and testing. The model validation was carried out using a prototype named Environmental Educational Learning System (or EELS). Figure 1 shows the activities involved in each phase of this study.

\subsubsection{Phase 1: Conceptual design and requirement specification}

State-of-the-art green data models were reviewed and studied. This phase aimed to investigate the existing green data architecture and models and associated problems related to green environmental management issues-particularly regarding particles, noise, and vibration (PVN). Sample environmental data for quarries were gathered and analysed to understand the complex links in the information needed to achieve a green environment. A conceptual framework consisting of theoretical and practical 


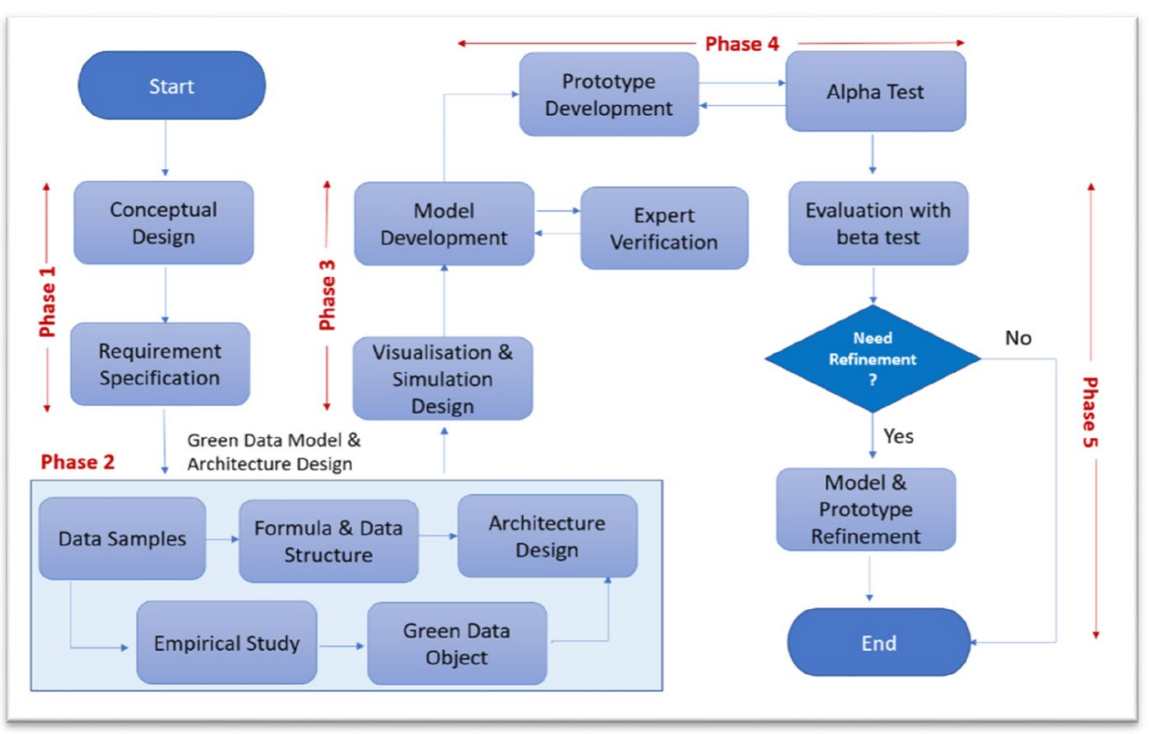

Fig. 1 Flowchart of research activities

data was constructed. Furthermore, based on the sample environmental data, the attributes and parameters of green data were identified and defined.

\subsubsection{Phase 2: Green data model and architecture design}

In this phase, the integrated green data object structure and definitions were formulated and tested at a certain optimisation level. Also, a normalisation technique for data representation was used to obtain a sustainable design for the proposed model structure. Furthermore, data processing was also done, including collecting, gathering, cleaning, filtering, exploring, transferring, and analysing the data to form welldefined, integrated quarry environmental data. Finally, the model architecture and data (metadata, classification, services) were developed and tested.

This activity was done collaboratively with our research collaborator, the Department of Mineral and Geoscience Malaysia (JMG). The JMG provided the data and liaised with the quarry industry for site visits and environmental experts. Two field works involving quarry site visits were carried out and collaboratively involved two limestones quarries in Perak, Malaysia. The objectives of the visit were to observe and understand the actual quarry activities closely.

During this phase, an empirical study was conducted to verify the components needed for the model. A semi-structured interview was conducted via an accepted method for obtaining experts' opinions about this issue. The experts who collaborated in this study were from the computing, education, and environmental domains. The detail of this empirical study and the findings are available in Fadzli et al. (2020). 


\subsubsection{Phase 3: Visualisation and simulation design and model development}

With well-defined, integrated environment objects, a workable repository structure was designed, developed, and tested in the context of achieving a green and sustainable environment. The architecture of the system prototype was constructed. Furthermore, the simulation and visualisation technique for environmental data suited to an educational, environmental learning system (or EELS) and targeted high school children were identified. Based on the findings from the previous phase, the components of the model were constructed. The proposed model was named the PRInK model, which stands for Learning the Impact of the Quarry Industry on the Environment in the Malay language. There were two main activities in the model development: identify the components and elements and verify them through expert review and confirmation.

\subsubsection{Phase 4: EELS prototype design and development}

This phase targeted the completion of the EELS prototype design. The design and development applied a systematic design and development approach involving architectural, interface, database, and component design. The services were defined to fulfil educational software requirements. A process for mapping the PRInK model to the system design was also done. An alpha test was conducted in a lab using sample data collected in Phases 1 and 2.

\subsubsection{Phase 5: Evaluation in confirmation study}

The proposed PRInK model was validated using the EELS prototype. During the beta testing, two groups of students from two schools in Selangor were invited to use and test the EELS. The EELS was subjected to real-world data, and system testing by the intended users improves the system. The users' experiences of EELS and the evaluation feedback were forwarded to the team for further model refinement.

\section{Results-a model for environmental virtual interactive based education and learning for STEM motivation (PRInK model)}

In the literature review, five main components of PRInK were identified: ComputerAssisted Learning (CAL), Problem Context (scenario), Learning and Knowledge Score (Outcomes), Motivation Level, and Environmental Data. The verification process through expert verification has confirmed the above components.

The STEM education elements incorporated in this study encourage the students to inquire and explore the environment by exploring and enquiring about real-world scenarios. Integrating $\mathrm{S} \& \mathrm{~V}$ and $\mathrm{CAL}$ enables students to create real-world elements through simulation that would otherwise be too difficult, dangerous or time-consuming in a conventional learning setting. The environmental impact of quarry activities 
is a real-world problem facing Malaysia today. Since the country has numerous quarries, society must be aware of the effects of these quarry activities on the environment and themselves.

This study simulated natural process outcomes by integrating environmental data objects or green environmental data using specific input parameters. The integrated data objects were defined and incorporated into a primary repository and computational model, so they are easily accessible, handled, and shared with various user groups, besides serving as valuable scientific data (Yahaya et al., 2016; Yahaya et al., 2017; Yahaya et al., 2019). The proposed model and S\&V can readily use and utilise the repository. This study also employed the 5E instructional model and green environmental data to design the $\mathrm{S} \& \mathrm{~V}$ embedded in the PRInK model. Per the above discussion, students go through 5 stages when learning using the $5 \mathrm{E}$ instructional model: the engagement phase, the exploration phase, the explanation phase, the elaboration phase, and the evaluation phase. Each step has a specific objective, aiming to motivate the students to learn about quarry activities through simulation. This integrated, hybrid model for learning about the quarry's industrial impact on the environment embeds the 5E instructional model as the pillars of the PRInK model. Figure 2 shows the proposed PRInK model and the 5E pillars for instructional and motivational assessment.

The simulation developed in this study requires a system that adapts to different scenarios. To this end, mathematical modelling, inquiry-based learning, and toolbased experimental lessons can be used simultaneously to provide possible STEM learning and education, but these tools are not enough. Therefore, this study developed a computational model to simulate the green environmental data to represent the natural processes involved in quarry activities. Students can then use this model

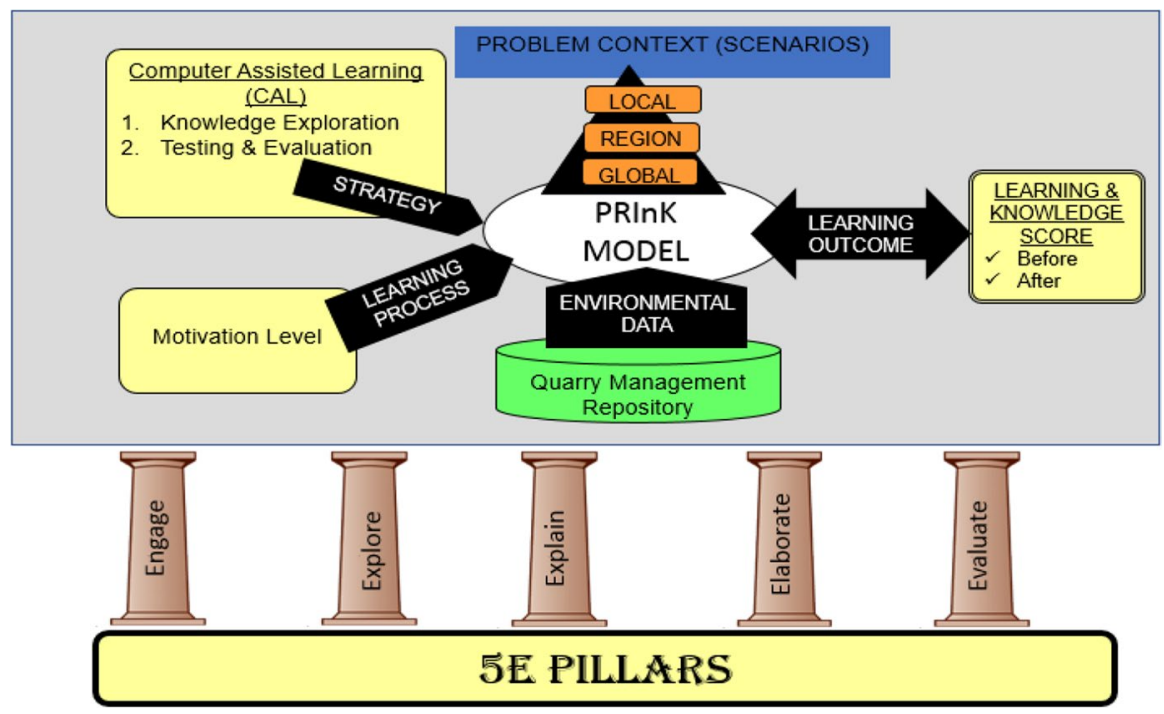

Fig. 2 The Environmental Virtual Interactive Based Education and Learning Model for STEM Motivation (or PRInK model) 
for knowledge discovery and manipulation. The main scenarios simulated in the computational model are quarrying activities: blasting, crushing, transportation, drilling, and material handling. The proposed S\&V tools enable the users to manipulate and discover complex and realistic green environmental data involved in quarrying scenarios. Students will learn new skills and knowledge as part of the learning outcome when exposed to this learning environment.

The PRInk model comprises five main components:

i. Computer-Assisted Learning (CAL): This component aligns with the 5E pillars that help students involved in CAL to explain the topic under study further and understand advanced issues and subjects. To this end, the CAL strategy is used for knowledge exploration, and testing and evaluation.

ii. Problem Context (the scenarios): Students can learn about various STEM concepts with successful S\&V. However, successful S\&V requires investigating a system that adapts to different scenarios. Students can visualise time-consuming, dangerous environments, such as earthquake disasters and environmental planning, manufacturing and business activities, and construction planning when exploring these scenarios. Hence, these $S \& V$ scenarios could be applied locally, regionally, and globally.

iii. Motivation Level: Through the engagement phase in the 5E pillar, the student motivation level can be encouraged using simulation and visualisation and can be measured through knowledge assessment.

iv. Environmental Data and Repository: In the elaboration phase of this 5E pillar, students can elaborate on their understanding of a concept by applying environmental data in new situations. The actual ecological data are used and applied in several cases. Students can manipulate the circumstances by applying different inputs and parameters. The quarrying activities are chosen because they involve various scenarios related to everyday life and have local, regional, and global implications. The environment data stored in the repository was captured based on green environment data collected previously.

v. Learning and Knowledge Score: In the evaluation phase, the learning outcomes are assessed. Therefore, student knowledge and motivation level are evaluated based on scores generated before and after the learning activity.

The PRInK model was mapped to the Environmental Educational Learning System (or EELS) prototype. Figure 3 shows the EELS architecture.

The data captured and generated through EELS are stored in the database comprising a knowledge test bank, student scores, and quarry computational data. As for the EELS prototype architecture, students may log in to the system and access the student role. There is also another role in this system, which is the administrator role. The administrator has privilege-level access to the whole system and database. If the user is a student, they must go through a testing module where random test questions will be extracted and retrieved from the database. Once finished with the testing module, the student will explore the quarry activities and experience the $5 \mathrm{E}$ learning model. After going through all the activities, another testing method is 


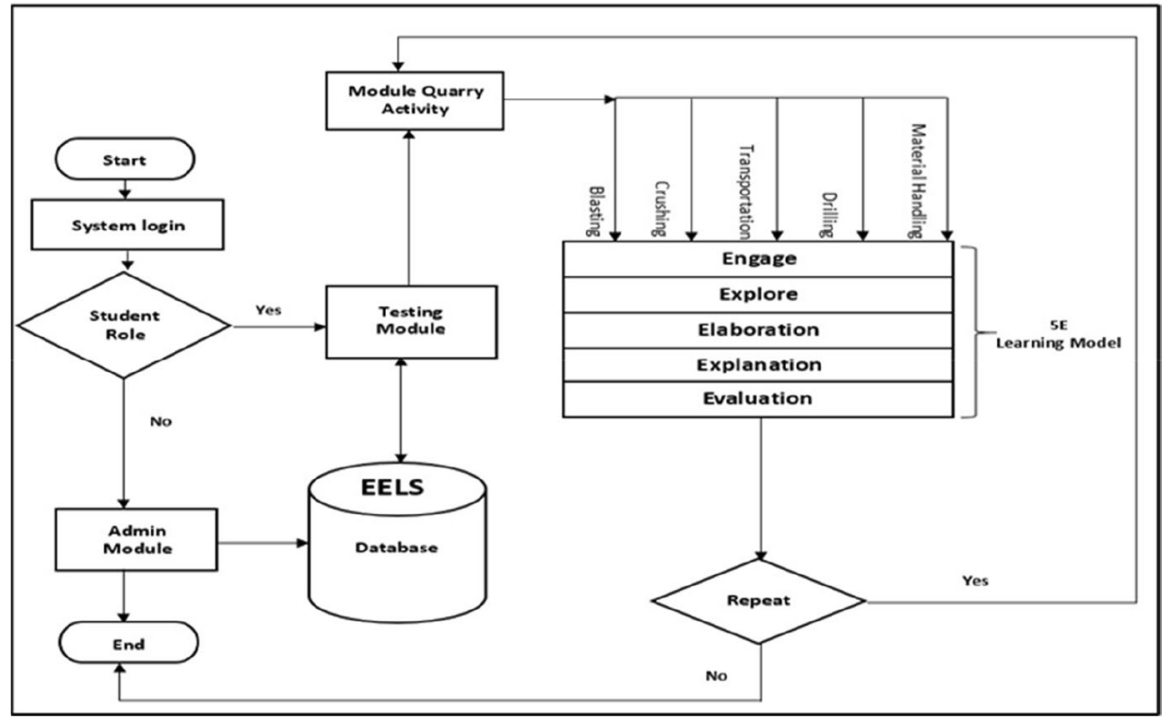

Fig. 3 The EELS prototype architecture

carried out in the evaluation stage of the 5E learning model. The evaluation retrieves random test bank data.

\section{Validation}

Experts were invited to collaborate and verify the PRInK components as discussed in (Fadzli et al., 2020). Further, the validation was carried out with real users of EELS to assess EELS' usability. EELS was developed as a prototype based on the PRInK model. According to Kabir et al. (2017), the usability assessment is essential to validate the quality of a specific model. Based on ISO 9241-11, usability refers to "the extent to which specified users can use a system, product, or service to achieve specified goals with effectiveness, efficiency, and satisfaction in a specified context of use." After the validation process, any weaknesses and comments were corrected and refined accordingly.

The usability measure was assessed based on four factors: learnability, effectiveness, efficiency, and satisfaction (Sengel, 2013). In this study, the usability measurements were evaluated in two stages of validation: expert validation and user validation.

a) The first stage of validation involved experts participating in this study. A workshop was conducted and attended by the experts and project members to give comments and feedback on the EELS prototype to enhance and refine it further. Based on the input from the experts, several aspects of improvement were identified, such as the usage of sentences in the scenarios, graphic display, and the 
suitability of graphics and photos that would impact the users. The improvement and refinement were implemented before the validation with actual users took place.

b) The second stage of validation involved school children from high schools in Selangor, Malaysia. The two schools were selected based on convenient sampling and a close locality to the research centre. The validation and assessment instrument consisted of design, content, and organisation, multimedia, and effectiveness. The measurements were adopted from Nawi and Zakaria (2016) and used to measure characteristics and usability. Table 1 shows the usability measurement used in this study.

The assessment criteria were used to obtain the level of agreement on user satisfaction. Therefore, the Likert scale point was applied to get an agreement level, proven suitable for this purpose. The Likert scale uses 1-Strongly Disagree (SD); 2- Disagree (D); 3-Almost Agree (AA); 4-Agree(A); 5-Strongly Agree (SA). In addition, data analysis was simplified by categorising the mean score, as shown in Table 2.

Meanwhile, the interpretation of the mean score is shown in Table 3.

\subsection{Validation of the model via the prototype}

Validation aims to confirm prototype usability. The number of school children involved in this activity is 21 , which are referred to as respondents. They are high schools' students in Form IV and age 16 years old. They were asked to answer the assessment questions as shown in Table 1 after exploring the EELS prototype. The results are shown in Table 4 . It shows the mean score obtained by the usability elements given by the respondents in this study. The mean score for the design element was $4.56 / 5.00$, so the respondents strongly agreed with this element.

Similarly, for element organisation and content, the mean score was 4.18/5.00 (strongly agree). The same goes for the multimedia element 3.97/5.00 (strongly agree) and effectiveness 4.17/5.00 (strongly agree). This result is represented in a bar chart in Fig. 4. It shows that the users agreed that the EELS prototype had significant usability measures.

\subsection{Testing student knowledge and awareness}

In addition to the model and prototype validation, this study proved that by using and exploring the EELS prototype, the respondents' knowledge and awareness of quarry activities and their impact on the green environment and society also increased. The sample of statements used to test the knowledge and understanding of the school children before and after exploring the EELS prototype are shown in Table 5. The students answered each question based on the Likert scale 1-Strongly Disagree; 2Disagree; 3-Almost Agree; 4-Agree; 5-Strongly Agree. 


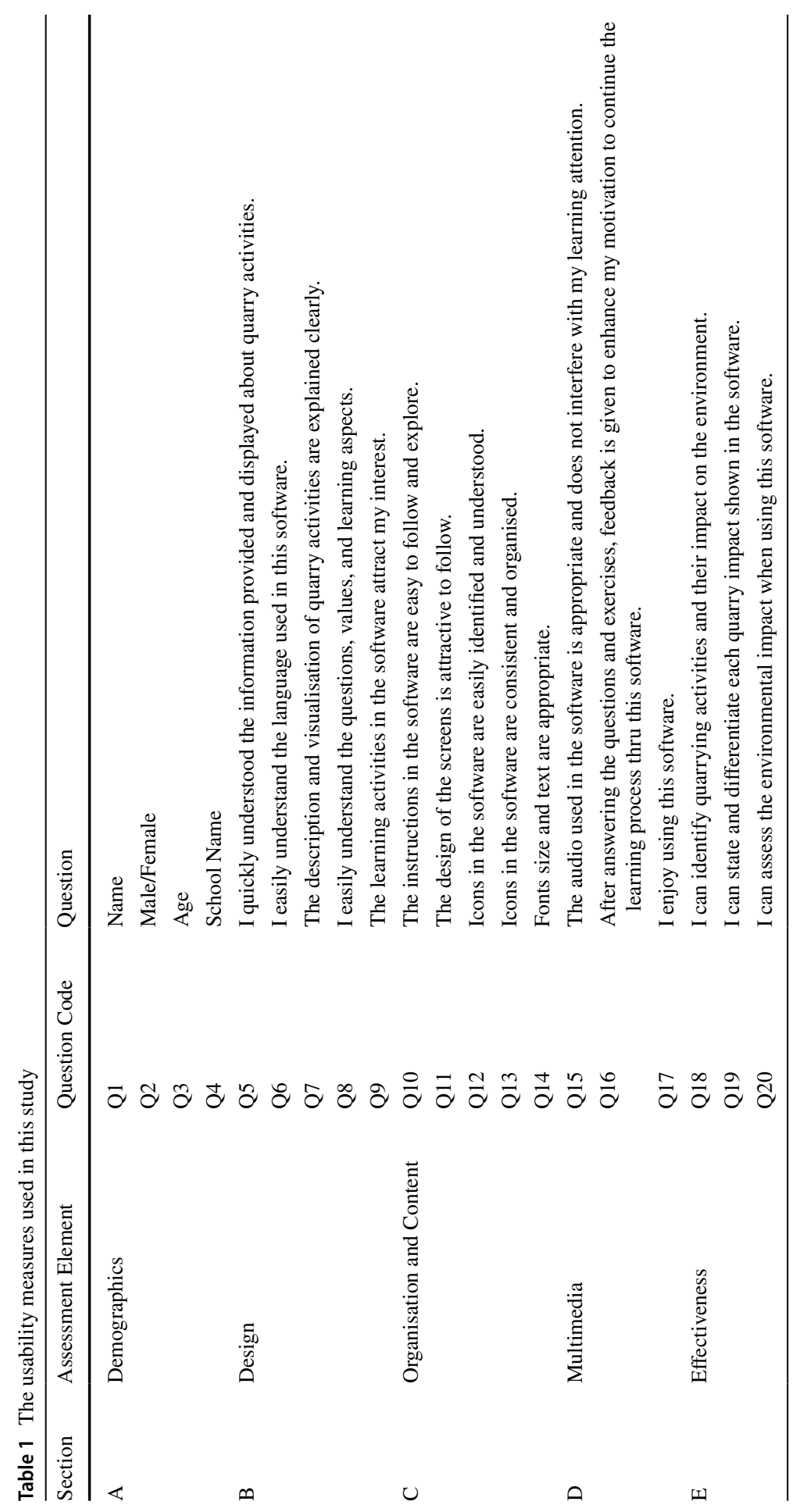


Table 2 Likert scale category

\begin{tabular}{llllll}
\hline Score & 1-SD & 2-D & 3-AA & 4-A & 5-SA \\
\hline Agreement Category & Disagree & & Agree & & \\
\hline
\end{tabular}

Table 3 Interpretation of mean score

\begin{tabular}{lll}
\hline Mean Score Range & Level of agreement & Interpretation \\
\hline $1.00-2.33$ & Low level of agreement & Disagree \\
$2.34-3.66$ & Moderate level of agreement & Partial Agree \\
$3.67-5.00$ & High level of agreement & Strongly Agree \\
\hline
\end{tabular}

Table 4 The respondent usability assessment

\begin{tabular}{|c|c|c|c|c|c|c|c|c|}
\hline \multirow[t]{2}{*}{ Element } & \multirow[t]{2}{*}{ Question } & \multicolumn{5}{|c|}{$\begin{array}{l}\text { Likert scale Chosen in Percent- } \\
\text { age }(\%)\end{array}$} & \multirow{2}{*}{$\begin{array}{l}\text { Mean by } \\
\text { Ques- } \\
\text { tion }\end{array}$} & \multirow[t]{2}{*}{ Total Mean by Element } \\
\hline & & SD & $\mathrm{D}$ & AA & A & SA & & \\
\hline \multirow[t]{5}{*}{ Design } & Q5. & & & & 23.81 & 76.19 & 4.8 & \multirow{5}{*}{$\begin{array}{l}4.56 \\
\text { Strongly Agree }\end{array}$} \\
\hline & Q6. & & & & & 100 & 5.0 & \\
\hline & Q7. & & & 19.05 & 57.14 & 23.81 & 4.0 & \\
\hline & Q8. & & & & 27.57 & 71.43 & 4.7 & \\
\hline & Q9. & & & & 71.43 & 28.57 & 4.3 & \\
\hline \multirow{5}{*}{$\begin{array}{l}\text { Organisation and } \\
\text { Content }\end{array}$} & Q10. & & & & 76.19 & 23.81 & 4.2 & \multirow{5}{*}{$\begin{array}{l}4.18 \\
\text { Strongly Agree }\end{array}$} \\
\hline & Q11. & & & 9.52 & 19.05 & 71.43 & 4.6 & \\
\hline & Q12. & & & & 71.43 & 28.57 & 4.3 & \\
\hline & Q13. & & & 23.81 & 71.43 & 4.76 & 3.8 & \\
\hline & Q14. & & & 9.52 & 76.19 & 14.29 & 4.0 & \\
\hline \multirow[t]{3}{*}{ Multimedia } & Q15. & & & 28.57 & 61.9 & 9.52 & 3.8 & \multirow{3}{*}{$\begin{array}{l}3.97 \\
\text { Strongly Agree }\end{array}$} \\
\hline & Q16. & & & 19.05 & 66.67 & 14.29 & 4.0 & \\
\hline & Q17. & & & 9.52 & 71.43 & 19.05 & 4.1 & \\
\hline \multirow[t]{3}{*}{ Effectiveness } & Q18. & & & 4.76 & 80.95 & 14.29 & 4.1 & \multirow{3}{*}{$\begin{array}{l}4.17 \\
\text { Strongly Agree }\end{array}$} \\
\hline & Q19. & & & 9.52 & 85.71 & 4.76 & 4.0 & \\
\hline & Q20. & & & & 57.14 & 42.86 & 4.4 & \\
\hline
\end{tabular}

The knowledge and awareness assessment was conducted before the respondents used the prototype and finished with the exploration. The results show an increase in the respondents' mean scores except for S8 and S9. The increase in the mean score indicates increased knowledge and awareness. After exploring the EELS prototype, their answer to the questions or agreement with the correct statements demonstrated the result. The decrease in mean score for Statement S8 shows that the respondents in this study disagree with this statement after exploring the prototype, which is deemed correct. Meanwhile, in statement S9, the students feel that the quarry activities do not affect the school activities. These results are shown in Fig. 5. 


\section{Usability Measures by Mean Score}

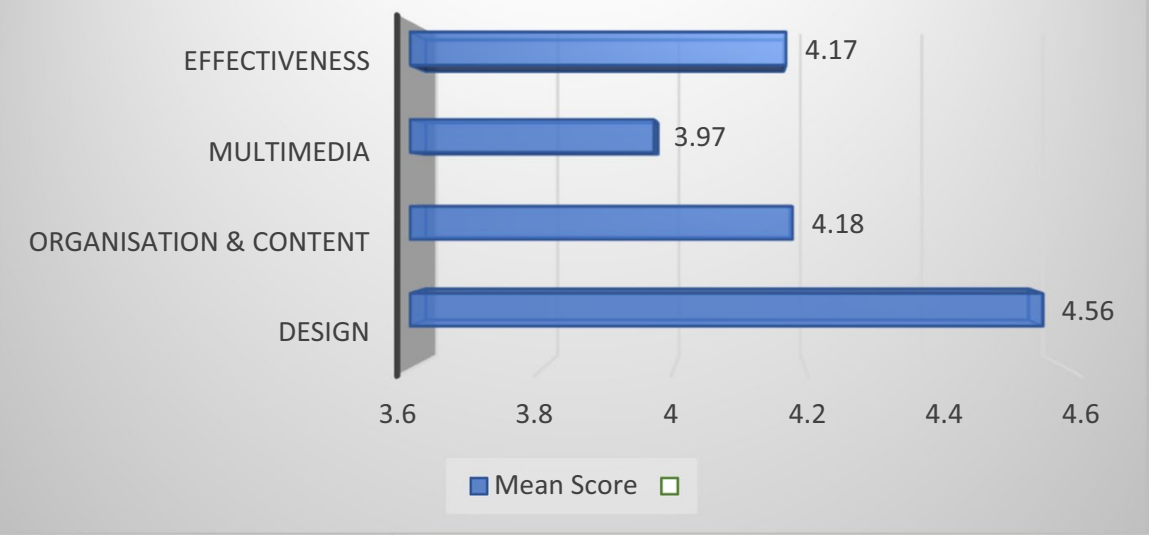

Fig. 4 The usability measures and elements by the mean score

Table 5 Sample of statements to test respondent knowledge and awareness regarding quarries and the environment

S1 Your familiarity with the quarry is broad and knowledgeable.

S2 I think the quarry affects our everyday life.

S3 I can explain the quarry activities using my own words.

S4 The quarries are essential for the development of our country.

S5 I know the effects and sources of pollutions from quarry activities.

S6 The quarry practitioners and the authority provide assurance and guarantee that the quarry environment and surroundings are safe and healthy from pollution, vibration, and noise.

S7 The quarry practitioners are always trying to reduce the impact of quarrying activities on the environment and society.

S8 The water quality of rain in the quarry environment is safe and drinkable.

S9 The quarry activities affect learning activities at school.

S10 I understand the activities in the quarry, such as blasting, drilling, and crushing.

\section{Discussion}

A model for learning about the quarry's industrial impact on the green environment or PRInK model was presented in this paper. There are five components in this model: a) computer-assisted learning (CAL); b) motivation level; c) green environmental data; d) learning outcome; and e) problem context. The simulation and visualisation were applied to green environmental data as actual scientific data. STEM education encourages the students to inquire and explore the environment by exploring and enquiring about real-world scenarios. Integrating S\&V and CAL enables students to create real-world elements through simulation that would otherwise be too difficult, dangerous, or time-consuming in a conventional learning setting. 


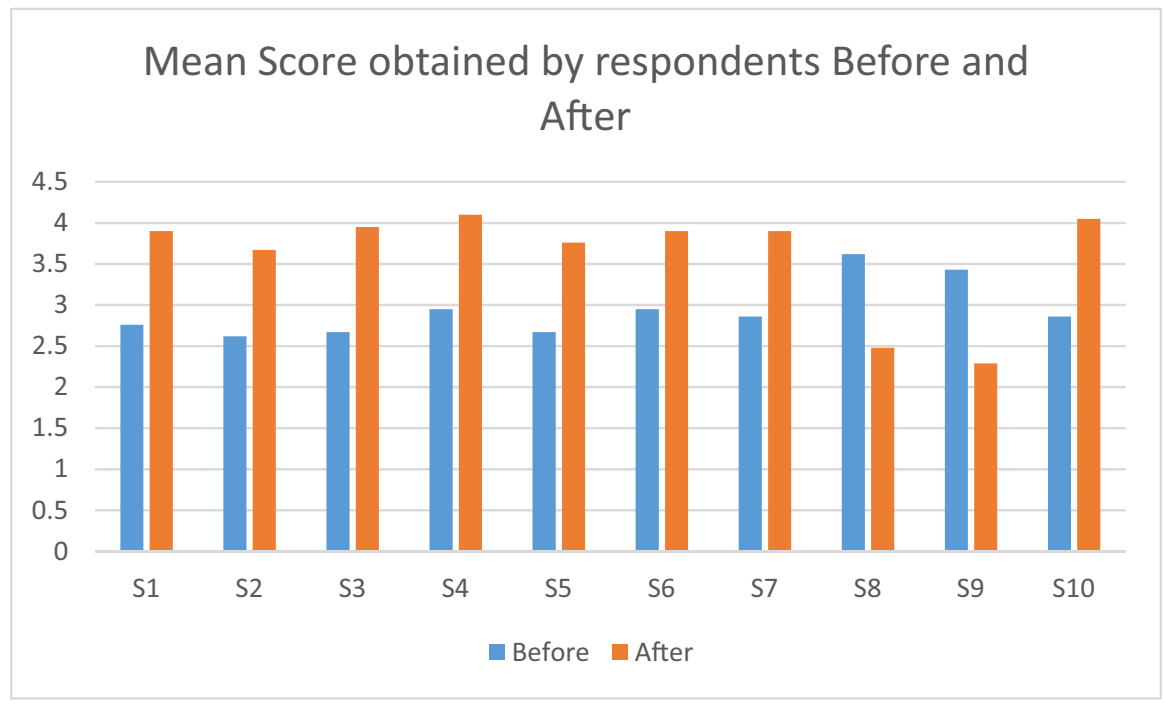

Fig. 5 The mean score obtained by the respondents Before and After using the prototype

The environmental impact of quarry activities is a real-world problem facing many countries. Since there are numerous quarries, society must be aware of the effects of these quarry activities on the environment and themselves.

This study simulated natural process outcomes by integrating environmental data objects or green environmental data using specific input parameters. The integrated data objects were defined and incorporated into a primary repository and computational model. As a result, they are easily accessible, handled, and shared with various user groups, besides the critical scientific data. Thus, $\mathrm{S} \& \mathrm{~V}$ can readily use the available and defined repository and data discussed in this paper.

The importance of $\mathrm{S} \& \mathrm{~V}$ as a tool to motivate students to learn has been proven in previous works. Hence, the extent of interactions in the simulation sessions could influence student motivation levels. The integration of the $5 \mathrm{E}$ instructional model and green environmental data produced a comprehensive simulation and visualisation design. Students must go through 5 stages of the $5 \mathrm{E}$ instructional model: engagement phase, exploration phase, explanation phase, elaboration phase, and evaluation phase. Each step has a specific objective, aiming to motivate the students to learn about quarry activities through simulation and visualisation techniques.

Mathematical modelling, inquiry-based learning, and tool-based experimental lessons can be used simultaneously to provide possible STEM learning and education, but these tools are not enough. Therefore, we developed a computational model to simulate the green environment data to represent the natural processes involved in quarry activities. The main scenarios simulated in the computational model are quarrying activity scenarios, including blasting, crushing, transportation, drilling, and material handling. The proposed $\mathrm{S} \& \mathrm{~V}$ tool lets users manipulate and discover the complex and realistic green environmental data in quarrying scenarios. Students will learn new skills and knowledge as part of the learning outcomes when exposed to this learning environment. 
The components of the PRInK model were verified and validated through expert verification and user validation. The experts agreed and proved all the details and features in two sessions conducted before and after the model development. The model was mapped into a prototype (EELS) and later validated via user validation. The high school students were chosen to participate in the validation activity. They approved the usability of the prototype and thus validated the proposed model.

This study is specifically proposed an instructional design model based on the secondary school syllabus in Malaysia. Further study needs to be conducted to generalise the model. However, the model can be applied to any form of the education system since the study's basis was to promote students' awareness of environmental issues using a virtual approach. The PRInK model and EELS application will ensure unlimited access to the subject with minimum operating costs.

\section{Conclusions and limitations of study}

This study develops an environmental virtual interactive-based education and instructional model for STEM motivation or PRInK model. The integration of simulation and visualisation of environmental data and the $5 \mathrm{E}$ instructional model was introduced, developed, and further validated through a collaboration with the Ministry of Education Malaysia. The 5E instructional model and the simulation and visualisation integration enable the exploration of virtual interactive based software for better empowerment of $S \& V$ development. In the education aspect, the integration allows knowledge investigation of the industrial quarry's impact on the environment in five stages: engagement, exploration, explanation, elaboration, and evaluation. The PRInK model and the embedded components were validated and verified through expert review and the EELS prototype development. The features of the PRInK model were mapped correctly into appropriate functions and modules and thus was successfully validated by the actual users of the system.

Furthermore, this study recommends developing a learning tool that can be used as an assisted learning material for subjects related to the environment and science. It can also be applied to any topic by adjusting the scope and data resources. The limitation of this study is that the implementation was carried out to enhance STEM motivation among upper secondary school students in Malaysia. And we used data, formulas and algorithms by the quarrying operations confirmed by the Department of Mineral and Geoscience Malaysia. Future works can be carried out by applying prediction model or big data analytics to enhance the algorithms in the model and use them in a bigger group of users. Similar simulation and visualisation tools can be applied using a different set of data from other countries as part of the instructional material related to environmental awareness and STEM motivation.

Acknowledgements This work was supported by Universiti Kebangsaan Malaysia Arus Perdana Grant (AP-2017-005/3) and Malaysia Ministry of Higher Education, Fundamental Research Grant Scheme (FRGS/1/2019/ICT01/UKM/02/1). In addition, we thank the Department of Mineral and Geoscience Malaysia, Ministry of Energy and Natural Resources Malaysia for the collaboration. 
Authors' contributions CRediT author statement: Jamaiah Yahaya: Conceptualisation, Writing Review and Edit, Supervisor, Funding Acquisition, Project Administration. Sazrol Fadzli: Writing Original Draft, Investigation, Formal Analysis, Software. Aziz Deraman: Methodology, Investigation, Validation. Noor Zaitun Yahaya: Data Curation. Lilia Halim: Investigation, Formal Analysis. Izhar Abadi: Resources, Data Curation. Siti Rohana: Validation, Project Administration.

Funding This work was supported by Universiti Kebangsaan Malaysia Arus Perdana Grant (AP-2017005/3) and Malaysia Ministry of Higher Education, Fundamental Research Grant Scheme (FRGS/1/2019/ ICT01/UKM/02/1).

Availability of supporting data Not applicable.

Code availability Not Applicable.

\section{Declarations}

Competing interests The authors have no relevant financial or non-financial interests to disclose.

Open Access This article is licensed under a Creative Commons Attribution 4.0 International License, which permits use, sharing, adaptation, distribution and reproduction in any medium or format, as long as you give appropriate credit to the original author(s) and the source, provide a link to the Creative Commons licence, and indicate if changes were made. The images or other third party material in this article are included in the article's Creative Commons licence, unless indicated otherwise in a credit line to the material. If material is not included in the article's Creative Commons licence and your intended use is not permitted by statutory regulation or exceeds the permitted use, you will need to obtain permission directly from the copyright holder. To view a copy of this licence, visit http://creativecommons.org/licen ses/by/4.0/.

\section{References}

Abdullah, S. I. S. S., Halim, L., \& Shahali, E. H. M. (2011). Integration of environmental knowledge across biology, physics and chemistry subject at secondary school level in Malaysia. Procedia Social Behavioral Science, 15, 1024-1028. https://doi.org/10.1016/j.sbspro.2011.03.233

Açişli, S., Yalçin, S. A., \& Turgut, Ü. (2011). Effects of the 5E learning model on students' academic achievements in movement and force issues. Procedia - Social Behavioral Science, 15, 2459-2462. https://doi.org/10.1016/j.sbspro.2011.04.128

Akkoyun, O. (2017). New simulation tool for teaching-learning processes in engineering education. Computer Applications in Engineering Education, 25(3), 404-410. https://doi.org/10.1002/cae.21807

Bahrum, S., Wahid, N., \& Nasir, I. (2017). Integration of STEM education in Malaysia and why to STEAM. International Journal of Academic Research in Business and Social Sciences, 7(6), 645654. https://doi.org/10.6007/IJARBSS/V7-I6/3027

Bilbokaite, R. (2016). Effect of computer based visualisation on motivation of the learning processes. Proceedings of EDULEARN16 Conference.

Cai, S., Wang, X., \& Chiang, F. (2014). A case study of augmented reality simulation system application in a chemistry course. Computers in Human Behavior, 37, 31-40. https://doi.org/10.1016/j.chb. 2014.04.018

Cantrell, P., Pekcan, G., Itani, A., \& Velasquez-Bryant, N. (2006). The effects of engineering modules on student learning in middle school science classrooms. Journal of Engineering Education, 95(4), 301-309. https://doi.org/10.1002/j.2168-9830.2006.tb00905.x

Chi, H., \& Jain, H. (2011). Teaching computing to STEM students via visualisation tools. Procedia Comput Science, 4(2), 1937-1943. https://doi.org/10.1016/j.procs.2011.04.211

Dawley, L., \& Dede, C. (2014). Situated learning in virtual worlds and immersive simulations. In Handbook of research on educational communications and technology (pp. 723-734). Springer New York. 
de Smale, S., Overmans, T., Jeuring, J., \& van de Grint, L. (2016). The effect of simulations and games on learning objectives in tertiary education: A systematic review. Lecture Notes in Computer Science (including subseries Lecture Notes in Artificial Intelligence and Lecture Notes in Bioinformatics), 9599, 506-516.

Fadzli, S., Yahaya, J., Deraman, A., Hamdan, A. R., Halim, L., Yahaya, N. Z., Zahari, M. S. M., \& Rais, I. A. I. (2020). Environment based virtual interaction to enhance motivation of STEM education: The qualitative interview design and analysis. Education and Information Technologies, 25(2), 775790. https://doi.org/10.1007/s10639-019-09996-y

Göksu, I., Özcan, K. V., Çakir, R., \& Göktas, Y. (2017). Content analysis of research trends in instructional design models: 1999-2014. Journal of Learning Design, 10(2), 85-109.

Greca, I. M., Seoane, E., \& Arriassecq, I. (2014). Epistemological issues concerning computer simulations in science and their implications for science education. Science Education, 23(4), 897-921. https://doi.org/10.1007/s11191-013-9673-7

Hidalgo-Céspedes, J., Marín-Raventós, G., \& Lara-Villagrán, V. (2016). Learning principles in program visualizations: A systematic literature review. Proc. - front. Educ. Conf. FIE, 2016-November. https://doi.org/10.1109/FIE.2016.7757692

Huang, B., Xiong, D., \& Li, H. (2004). An integrated approach to real-time environmental simulation and visualisation. Journal of Environmental Informatics, 3(1), 42-50. https://doi.org/10.3808/jei.200400026

Hung, L. J., Aliah, F., Abdullah, P., Abd, M., \& Bunyamin, H. (2013). Aplikasi Konsep Fizik Dalam Menyelesaikan Masalah Yang Berasaskan STEM Bagi Pelajar Tingkatan Enam Atas, 2nd International Seminar on Quality and Affordable Education (ISQAE 2013), 470-481.

ISO 14004 (2016) ISO 14004:2016 Environmental management systems — General guidelines on implementation, 3rd ed. 2016, pp. 1-59.

Kabir, M. A., Rehman, M. U., \& Majumdar, S. I. (2017). An analytical and comparative study of software usability quality factors. Proceedings of the IEEE international conference on software engineering and service sciences (ICSESS), 800-803. Beijing, China. https://doi.org/10.1109/ICSESS.2016. 7883188.

Lasiun M. (2016). Keberkesanan kaedah visualisasi: Meningkatkan keupayaan menyelesaikan masalah matematik berayat, Proc. ICECRS 1(1), 687-698. https://doi.org/10.21070/picecrs.v1i1.542.

Lee, W., \& Pachmayer, A. (2016). The impact of visualisation and expectation on tourists' emotion and satisfaction at the destination. Travel and Tourism Research Association: Advancing Tourism Research Globally, 12.

Liaw, S. Y., Scherpbier, A., Rethans, J. J., \& Klainin-Yobas, P. (2012). Assessment for simulation learning outcomes: A comparison of knowledge and self-reported confidence with observed clinical performance. Nurse Education Today, 32(6), e35-e39. https://doi.org/10.1016/j.nedt.2011.10.006

Lioce, L., et al. (2013). Standards of best practice: Simulation standard III: Participant objectives. Clinical Simulation in Nursing, 9(6 SUPPL), S15-S18. https://doi.org/10.1016/j.ecns.2013.04.005

Liu, S., Cui, W., Wu, Y., \& Liu, M. (2014). A survey on information visualisation: Recent advances and challenges. The Visual Computer, 30(12), 1373-1393. https://doi.org/10.1007/s00371-013-0892-3

Manser, M. J., \& Kilgo, J. W. (2015). Exploring the science of sound. Science Activities, 52(1), 15-24. https://doi.org/10.1080/00368121.2014.1002442

Ministry of Education Malaysia. (2015). Executive Summary Malaysia Education Blueprint 2015-2025 (Higher Education). Minist. Educ. Malaysia 2025, pp. 40.

Ministry of Education Malaysia. (2016). Panduan Pelaksanaan Sains, Teknologi, Kejuruteraan dan Matematik (STEM) dalam Pengajaran dan Pembelajaran guide for science, technology, engineering, and mathematics (STEM) in teaching and learning. Kementerian Pendidikan Malaysia.

Nawi, A., \& Zakaria, G. A. N. (2016). Pembangunan dan penilaian portal ipbl di Politeknik Brunei. Jurnal Komunikasi Malaysian Journal of Communication, 32(1), 261-285.

Persistent Organic Pollutants (POPs) Toolkit, POPs Toolkit Glossary. (2019). [Online]. Retrieved from http://www.popstoolkit.com/_glossary.aspx.

Pusat STEM Negara (2020). Model Pengajaran 5E (5E Instructional Model). https://www.facebook.com/ PSTEMN/posts/model-pengajaran-5emodel-ini-disarankan-untuk-digunakan-oleh-guru-dalam-melaksan/180236853667957/

Rosenzweig, E. Q., \& Wigfield, A. (2016). STEM motivation interventions for adolescents: A promising start, but further to go. Educational Psychologist, 51(2), 146-163. https://doi.org/10.1080/00461 520.2016 .1154792

Rutten, N., Van Joolingen, W. R., \& Van Der Veen, J. T. (2012). The learning effects of computer simulations in science education. Computer \& Education, 58(1), 136-153. https://doi.org/10.1016/j.compe du.2011.07.017 
Sattar, M., Rasul, M. S., \& Halim, L. (2016). Using stem integrated approach to nurture students' interest and 21st-century skills. The Eurasia Proceedings of Educational \& Social Sciences (EPESS), 4, 313-319.

Sengel, E. (2013). Usability level of a university website. Procedia - Social and Behavioral Sciences, 106, 3246-3252. https://doi.org/10.1016/j.sbspro.2013.12.373

Shahali, E. H. M., Halim, L., Rasul, M. S., Osman, K., \& Zulkifeli, M. A. (2017). STEM learning through engineering design: Impact on middle secondary students' interest towards STEM. Eurasia Journal of Mathematics, Science and Technology Education, 13(5), 1189-1211. https://doi.org/10.12973/ eurasia.2017.00667a

Śliwińska-Wyrzychowska, A., et al. (2015). Restored limestone quarry as an attractive place for educational purposes and refuge of biodiversity. General and Professional Education, 3, 31-37.

Smetana, L. K., \& Bell, R. L. (2012). Computer simulations to support science instruction and learning: A critical review of the literature. International Journal of Science Education, 34(9), 1337-1370. https://doi.org/10.1080/09500693.2011.605182

Srisawasdi, N., \& Panjaburee, P. (2015). Exploring effectiveness of simulation-based inquiry learning in science with integration of formative assessment. J. Comput. Educ., 2, 323-352. https://doi.org/10. 1007/s40692-015-0037-y

Standridge, C. R. (1985). Performing simulation projects with the extended simulation system (TESS). Simulation, 45(6), 283-291. https://doi.org/10.1177/003754978504500602

Stapa, M. A., \& Mohammad, N. (2019). The use of Addie model for designing blended learning application at vocational colleges in Malaysia. Asia-Pacific Journal of Information Technology and Multimedia, 8(1), 49-62. https://doi.org/10.17576/APJITM-2019-0801-05

Watson, K., Aubusson, P., Steel, F., \& Griffin, J. (1997). A culture of learning in the informal museum setting? J. Aust. Res. Early Child. Educ., 9(1), 125-138 http://hdl.handle.net/10453/5930

Yahaya, J. H., Deraman, A., Hamdan, A. R., Yahaya, N. Z., Mohamed Zahari, M. S., Ibrahim Rais, I. A., \& Harun, N. F. (2016). Environmental quarry system based on integrated digital objects: The conceptual model. Advanced Science Letters, 22(8), 1914-1918. https://doi.org/10.1166/as1.2016.7740

Yahaya, J. H., Deraman, A., Hamdan, A. R., Yahaya, N. Z., Rais, I. A. I \& Zahari, M. S. M. (2017). The computational model for environment quality measurement. IEEE Computing Conference 2017, 18-20 July 2017, London UK, 947-952. https://doi.org/10.1109/SAI.2017.8252208.

Yahaya, N. Z., Ibrahim, Z. F., \& Yahaya, J. H. (2019). The used of the boosted regression tree optimization technique to analyse air pollution data. International Journal of Recent Technology and Engineering (IJRTE), 8(4), 1565-1575.

Zelaya-Floyd, M. I. (2017). Exploring the role of simulation and visualisation tools in improving learning outcomes in support of technology programs. Clemson University.

Publisher's note Springer Nature remains neutral with regard to jurisdictional claims in published maps and institutional affiliations.

\section{Authors and Affiliations}

\section{Jamaiah Yahaya ${ }^{1}$ D . Sazrol Fadzli ${ }^{1}$ - Aziz Deraman ${ }^{2}$ - Noor Zaitun Yahaya ${ }^{2}$. Lilia Halim ${ }^{3}$ - Izhar Abadi Ibrahim Rais ${ }^{4}$. Siti Rohana Ahmad Ibrahim ${ }^{1}$}

1 Faculty of Information Science and Technology, Research Centre for Software Technology and Management, Universiti Kebangsaan Malaysia, Bangi, Selangor, Malaysia

2 Faculty of Ocean Engineering Technology and Informatics, Universiti Malaysia Terengganu, Kuala Terengganu, Terengganu, Malaysia

3 Faculty of Education, Universiti Kebangsaan Malaysia, Bangi, Selangor, Malaysia

4 Department of Mineral and Geoscience Malaysia, Mineral Research Centre, Ipoh, Perak, Malaysia 